\title{
Investigating organizational culture adaptability of broadcasting firm in response to environmental changes
}

\author{
Seyed Mohammad Reza Salehi ${ }^{\mathbf{a}^{*}}$, Naser Mirsepasi ${ }^{\mathrm{b}}$ and Ali Akbar Farhangi ${ }^{\mathrm{b}}$
}

${ }^{a} \mathrm{PhD}$ Graduate from Media Management Department, Science and Research Branch, Islamic Azad University, Tehran, Iran ${ }^{b}$ Faculty member, Media Management Department, Science and Research Branch, Islamic Azad University, Tehran, Iran

\begin{tabular}{|c|c|}
\hline C H R O N I C L E & A B S T R A C T \\
\hline $\begin{array}{l}\text { Article history: } \\
\text { Received March 5, } 2015 \\
\text { Received in revised format } \\
\text { August } 162015 \\
\text { Accepted September } 312015 \\
\text { Available online } \\
\text { October } 62015 \\
\text { Keywords: } \\
\text { Organizational change }\end{array}$ & $\begin{array}{l}\text { The primary objective of this paper is to study the present status of organizational adaptability } \\
\text { in Iranian broadcasting system against environmental changes and present possible suggestions } \\
\text { to empower the organization to cope with future changes. The study uses the method developed } \\
\text { by Denison (1990) [Denison, D. R. (1990). Corporate culture and organizational effectiveness. } \\
\text { John Wiley \& Sons.] to study the organizational changes. Using a sample of } 354 \text { randomly } \\
\text { selected employees who worked for this organization, the study has determined that the level } \\
\text { of organizational adaptability was less than desirable level and the firm needs to make } \\
\text { necessary actions to better cope with environmental change. }\end{array}$ \\
\hline
\end{tabular}

\section{Introduction}

During the past few years, there have been different studies, which indicate that organizations with appropriate culture tend to have better chance of success (James, 2003). Respect and understanding of the organizational culture and management in line with long-term goals and strategies of the organization can have a significant impact on the growth and development of organizations and the development of the competitive advantage. Organizational culture affects all aspects of the organizations. Studies show that culture may influence on goal setting, strategy, individual behavior, organizational performance, job satisfaction and motivation, creativity, decision-making and participation of employees, the dedication and commitment, hard work, etc. Studies also show that successful companies have strong organizational culture and effective organization phenomena in general (Denison \& Spreitzer, 1991). A good culture for an organization is similar to serving a nutrition food to people. It increases people's motivation and helps them become more creative. Lack of attention to corporate culture may slow down firm's movement towards it mission. Identifying and managing

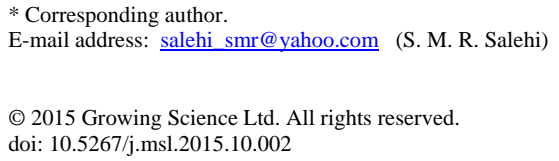


organizational culture helps managers have a complete view about firms' strengths and weaknesses. Organizational cultures includes norms, values, customs, traditions, samples, protocols and all these factors influence on all aspects of organization, personnel management duties and empower organizations. Organizational culture that is part of the internal environment describes a combination of a set of commitments, beliefs and values shared by the members of the organization, and guides employees to do their duties (Lacatus, 2013).

Baier et al. (2015) analyzed the effects of captive offshoring of innovation activities on the organizations' ability to adapt their organizational structures. They reported a reverse u-shape of innovation offshoring on the effectiveness of organizational adaptability, indicating an optimal threshold value of innovation offshoring. They also showed that the expenses of innovation offshoring in terms of reduced organizational adaptation could be increased by a regional dispersion of the offshoring activities and strong embeddedness in onshore networks.

Low et al. (2015) investigated the relationship between organizational culture and international bidding decisions with association to the political and economic risks of Malaysian international contractors. They reported that organizational culture casts the effect on international bidding decisions. Albayrak and Albayrak (2014) "the organizational culture of the construction industry" was discussed and reported that organizational culture could boost the value of Turkey's construction sector in national and international context.

Yilmaz and Ergun (2008) investigated organizational culture and firm effectiveness by performing a survey on relative effects of culture traits and the balanced culture hypothesis in an emerging economy. Azanza et al. (2013) investigated how flexibility-oriented organizational cultures could facilitate positive outcomes at the employee level through its effect on authentic leadership. They explained that authentic leadership partially could mediate the positive relationship between flexibilityoriented organizational cultures and employees' job satisfaction. Yesil and Kaya (2013) studied the role of organizational culture on firm financial performance based on the data gathered from managers of the organizations in Gaziantep in Turkey. They reported that organizational culture dimensions had no impact on firm financial performance. Aktaş et al. (2011) reported that organizational culture kinds were associated with some organizational efficiency dimensions. Ebrahimpour et al. (2011) investigated the relationship between organizational culture and organizational citizenship behavior by building a model for improving organizational citizenship behavior.

\section{The proposed study}

This paper investigates the present status of organizational adaptability in Iranian broadcasting system against environmental changes and present possible suggestions to empower the organization to cope with future changes. The study uses the method developed by Denison $(1990,2000)$ to study organizational changes. The questionnaire of this survey consists of five general questions about participants' personal characteristics and 15 questions in 1-5 Likert scale, which measures different perspectives of organizational adaptability. The questionnaire was first distributed among some experts to make sure that they were clearly stated and next 20 questionnaires were given to some randomly selected participants in our survey. Cronbach alpha has been calculated as 0.724 , which is well above the minimum acceptable level of 0.70 and it confirms the reliability of the survey. Finally we assume the population follows a normal distribution. Therefore we could use the following formula to calculate the minimum number of sample size,

$$
n=\frac{N \times z_{\alpha / 2}^{2} \times p \times q}{\varepsilon^{2} \times(N-1)+z_{\alpha / 2}^{2} \times p \times q},
$$


where $N$ is the population size, $p=1-q$ represents the yes/no categories, $z_{\alpha / 2}$ is CDF of normal distribution and finally $\varepsilon$ is the error term. Since we have $p=0.5, z_{\alpha / 2}=1.96$ and $N=2600$, the number of sample size is calculated as $n=384$. The primary hypothesis of the survey investigates whether or not organizational adabpatablity in Iranian broadcasting organization is in desirable. To answer this question, we need to find out whether or not the changability, customer orientation and organizational learning in this organization are desirable. Table 1 demonstrates some of the basic statistics about these three factors.

Table 1

The summary of some basic statistics

\begin{tabular}{clccc}
\hline Item & Organizational adaptability & Mean & Variance & Standard deviation \\
\hline 1 & Changeability & 2.6716 & 0.324 & 0.56914 \\
2 & Customer orientation & 2.6432 & 0.338 & 0.58115 \\
3 & Organizational learning & 2.7727 & 0.347 & 0.58892 \\
\hline
\end{tabular}

As we can observe from the results of Table 1, organizational learning maintains the highest mean followed by changeability and customer orientation. The study uses binomial test to examine the hypotheses of the survey.

\section{The results}

The implementation of binomial test on measuring the effects of organizational adaptability components including changeability, customer orientation and organizational learning has indicated that none of these components is in desirable level. Table 2 shows details of our findings.

\section{Table 2}

The summary of the results of binomial test

\begin{tabular}{lllccccc}
\hline \multicolumn{1}{c}{$\mathrm{H}_{0}$} & \multicolumn{1}{c}{$\mathrm{H}_{1}$} & $\mathrm{P}$ & Test & Sig. & Error & Result $\mathrm{H}_{0}$ \\
\hline 1 & Changeability is desirable & Changeability is not desirable & 0.23 & 0.5 & 0 & 0.05 & Rejected \\
2 & Customer orientation is desirable & Customer orientation is not desirable & 0.23 & 0.5 & 0 & 0.05 & Rejected \\
3 & Organizational learning is desirable & Organizational learning is not desirable & 0.28 & 0.5 & 0 & 0.05 & Rejected \\
\hline
\end{tabular}

According to the results of Table 2, none of three components of the survey is in desirable level. In other words, the experts participated in our survey believe that organization is not able to make changes needed promptly, is not capable of being customer oriented and organizational learning is not within desirable level. Finally, we have implemented Freedman test to rank different components of the survey. In our survey, Chi-Square has been calculated as 11.431 with Sig. $=0.000$. According to our survey, organizational learning is the most important factor followed by changeability and customer orientation.

\section{Conclusion}

There is no doubt that media in the present century has been changing rapidly and multi media organizations need to cope with changes, quickly. When an organization learns on how make changes on its infrastructures, it can adapt with changes more quickly and possible lead to better customer orientation. In this survey, we have performed an empirical investigation to study the status of three main components of organizational adaptability. The results of our survey have confirmed that the Iranian national broadcasting channel was not in good conditions in terms of organizational adaptability. In our survey, it was cleared that organizational learning was the most important factor and the management team needs to pay especial attention on empowering its employees. The survey has also indicated that customer orientation and changeability were not in desirable level. The organization needs to select suitable personnel with good training and retraining programs. The firm also needs to have continuous evaluation of audiences' comments, measure audiences' satisfaction. 
The organization has to use technology to achieve customers' expectations. The firm must create a suitable atmosphere for creativity and innovation and employees with good innovative ideas must be rewarded, accordingly. Employees also have to be encouraged to participate in learning programs and people with better educational background must be rewarded.

\section{Acknowledgement}

The authors would like to thank the anonymous referees for constructive comments on earlier version of this paper.

\section{References}

Albayrak, G., \& Albayrak, U. (2014). Organizational culture approach and effects on Turkish construction sector. APCBEE Procedia, 9, 252-257.

Aktaş, E., Çiçek, I., \& Kıyak, M. (2011). The effect of organizational culture on organizational efficiency: The moderating role of organizational environment and CEO values. Procedia-Social and Behavioral Sciences, 24, 1560-1573.

Azanza, G., León, J. A. M., \& Alonso, F. M. (2013). Authentic leadership and organizational culture as drivers of employees job satisfaction. Revista de psicología del trabajo y de las organizaciones= Journal of Work and Organizational Psychology, 29(2), 45-50.

Baier, E., Rammer, C., \& Schubert, T. (2015). The impact of captive innovation offshoring on the effectiveness of organizational adaptation. Journal of International Management, 21(2), 150-165.

Denison, D. R. (1990). Corporate culture and organizational effectiveness. John Wiley \& Sons.

Denison, D. R., \& Spreitzer, G. M. (1991). Organizational culture and organizational development: A competing values approach. Research in organizational change and development, 5(1), 1-21.

Denison, D. R. (2000). Organizational culture: Can it be a key lever for driving organizational change. The international handbook of organizational culture and climate, 347-372.

Ebrahimpour, H., Zahed, A., Khaleghkhah, A., \& Sepehri, M. B. (2011). A survey relation between organizational culture and organizational citizenship behavior. Procedia-Social and Behavioral Sciences, 30, 1920-1925.

James, C. R. (2003). Designing learning organizations. Organizational Dynamics, 32(1), 46-61.

Lacatus, M. L. (2013). Organizational culture in contemporary university.Procedia-Social and Behavioral Sciences, 76, 421-425.

Low, W. W., Abdul-Rahman, H., \& Zakaria, N. (2015). The impact of organizational culture on international bidding decisions: Malaysia context. International Journal of Project Management, 33(4), 917-931.

Yesil, S., \& Kaya, A. (2013). The effect of organizational culture on firm financial performance: Evidence from a developing country. Procedia-Social and Behavioral Sciences, 81, 428-437.

Yilmaz, C., \& Ergun, E. (2008). Organizational culture and firm effectiveness: An examination of relative effects of culture traits and the balanced culture hypothesis in an emerging economy. Journal of world business, 43(3), 290-306. 